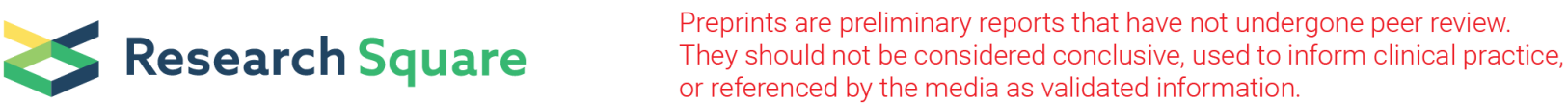

\section{Diaphragm Satellite Cells Isolation by Optimized MACS and the Effect of Mechanical Ventilation on their Proliferation and Differentiation Characteristics through MyoD and Myogenin Pathways}

Junying Ding ( 18211197728@163.com )

Beijing hospital of TCM https://orcid.org/0000-0003-1354-1343

Qian Li

McGill University Health Centre

Feng Liang

McGill University Health Centre

Salyan Bhattarai

McGill University Health Centre

Qingquan Liu

Beijing Hospital of Traditional Chinese Medicine

\section{Research}

Keywords: Mechanical Ventilation, Satellite cell, Diaphragm, Differentiation, MyoD

Posted Date: December 4th, 2020

DOI: https://doi.org/10.21203/rs.3.rs-117842/v1

License: (c) (1) This work is licensed under a Creative Commons Attribution 4.0 International License.

Read Full License 


\section{Abstract}

Objective: In the present study, we aimed to establish a feasible method to isolate single diaphragm satellite cells from C57 mice, and clarify the effect of mechanical ventilation (MV) on the proliferation and differentiation of diaphragm satellite cells. Moreover, the underlying molecular mechanism was also explored.

Methods: After the dissection of the diaphragm, enzymolysis, and specific antibody selection, single diaphragm satellite cells were harvested from C57 mice receiving $6 \mathrm{~h}$ of MV or not with optimized magnetic-activated cell sorting (MACS) approach. The cells were stained with BrdU or labeled with the differentiation antibody $\mathrm{MYH} 3$, followed by observation using fluorescence microscopy. The cells were counted from randomly selected visual fields, and the proliferation or differentiation characteristics of the control and MV groups were compared by IMAGE software. Besides, the expressions of MyoD and myogenin were detected by quantitative real-time PCR ( $q R T-P C R)$.

Results: The single diaphragm satellite cells were successfully purified through MACS using a set of optimized parameters. Generally speaking, $1.5 \times 10^{5}$ cells could be harvested from a single diaphragm. Upon MV, the proliferation rate of diaphragm satellite cells was decreased from $88.74 \%$ to $81.92 \%$, while the differentiation rate was increased from $17.94 \%$ to $27.58 \%$. Moreover, the expressions of MyoD and myogenin were significantly up-regulated upon MV.

Conclusions: In our current work, an efficient method was successfully established to isolate single diaphragm satellite cells. After MV, the differentiation rate of diaphragm satellite cells tended to increase, and the expressions of MyoD and myogenin were up-regulated. Collectively, our findings provided valuable insights into further research and clinical target treatment.

\section{Background}

Mechanical ventilation (MV) can be life-saving but is also associated with adverse effects on the diaphragm muscle [1, 2]. Especially, weaning from MV is a challenging step during recovery from critical illness. Moreover, weaning failure is associated with increased morbidity and mortality, exposing patients to life-threatening complications again [3]. Accumulating evidence has indicated that the prolonged MV (1 week or longer) promotes respiratory muscle weakness due to both contractile dysfunction and atrophy, especially in the diaphragm [4-7], indicating that diaphragm dysfunction plays a key role in weaning failure from MV. Petrof BJ and Vassilakopoulo have termed such a condition as ventilatorinduced diaphragmatic dysfunction (VIDD) $[8,9]$.

The proliferation of diaphragm satellite cells is a promising driving force to reverse VIDD. It is well known that in muscle regeneration, satellite cells are a small population in myogenic stem cells and adult muscle. These cells are mitotically quiescent, while they can be activated following injury, leading to the production of myogenic precursor cells, or myoblasts to mediate the regeneration of muscle tissues [10]. It has been reported that satellite cells expressing paired box protein 7 (Pax7) are the primary myogenic 
cells required for skeletal muscle regeneration [11]. Moreover, CXCL12 (C-X-C motif chemokine ligand 12) can facilitate muscle regeneration and Pax7 expression after cardiotoxin-related muscle injury [12]. Previous studies have well documented the importance of proliferation and differentiation of satellite cells in MV-associated respiratory failure. Besides, the myogenic cells in dystrophic muscle display accelerated differentiation [13]. However, it remains largely unexplored whether such a phenomenon also happens in the diaphragm muscle.

Previous studies have shown that pro-myogenic factors or transplantation of muscle satellite cells (MuSCs) can enhance skeletal muscle regeneration [14]. Anti-IL-6R antibody can also promote skeletal muscle regeneration [15]. Heme oxygenase-1 (HO-1; Hmox1) can affect myoblast differentiation by inhibiting myomiRs [16]. Inspiratory muscle training can improve the weaning outcomes in mechanically ventilated patients [17]. Moreover, diaphragm satellite cells are myogenic cells with potentials for proliferation and differentiation [18]. If the targets of MV changing the growth characteristics of diaphragm satellite cells can be clarified, the corresponding well-directed enhancers or inhibitors will be selected, which can help patients recover better. Therefore, the effective isolation of diaphragm satellite cells is the first step of subsequent mechanism research. However, no study has reported an effective approach to obtain diaphragm satellite cells. In the present study, we established an optimized method to purify single diaphragm satellite cells, and the effects of MV on the proliferation and differentiation of satellite cells were also explored. Collectively, our findings provided valuable insights into targeted treatment.

\section{Materials}

Xylazine and pentobarbital sodium were provided by Mcgill University Health Center (Montreal, Canada). Magnetic-activated cell sorting (MACS) kit was obtained from Miltenyi, Germany. Fluorescence microscope was provided by Zeiss Axio ImagerM2, Germany.

\section{Methods}

\section{$1 \mathrm{MV}$ intervention}

The animal-related protocols used in the present study were carried out following the guidelines for animal care and approved by the institutional animal care and use committee (IACUC) of Mcgill University Health Centre, and the suffering of animals was minimized by all types of efforts according to recommendations proposed by the European Commission (1997). Male C57 mice (10 12 weeks of age) were housed under standard conditions (Mcgill University Health Center, Montreal, Canada).

Eight mice were randomly divided into two groups, control group and MV group. The mice in the control group were fasted for $6 \mathrm{~h}$, while free access to water was given. The animals in the MV group received $6 \mathrm{~h}$ of controlled MV using a previously described protocol. The duration of MV for $6 \mathrm{~h}$ was selected based on previous work showing a significant reduction in diaphragmatic force-generating capacity. Briefly, MV 
mice were anesthetized by intraperitoneal injection of xylazine $(10 \mathrm{mg} / \mathrm{kg}$ body weight) and pentobarbital sodium ( $50 \mathrm{mg} / \mathrm{kg}$ body weight) and then orally intubated. No neuromuscular-blocking agent was used.

The endotracheal tube was connected to a small animal ventilator (Minivent ${ }^{\circledR}$; Harvard Apparatus, Canada) with the following settings: fraction of inspired oxygen of 0.21 (room air), controlled volume mode with a tidal volume of $10 \mu \mathrm{L} / \mathrm{mg}$ body weight, respiratory rate of 150 to 170 breaths/min, and positive end-expiratory pressure level of 3 to $4 \mathrm{~cm} \mathrm{H}_{2} \mathrm{O}$ achieved by placing the expiratory port under a water seal. Animals were placed on a prewarmed homeothermic blanket (Homeothermic Blanket Control Unit; Harvard Apparatus), and the mice received hourly intraperitoneal injections of lactated Ringer's solution $(0.10 \mathrm{~mL})$ to compensate insensible losses. Besides, pentobarbital was administered every 1 to $1.5 \mathrm{~h}$ to maintain adequate anesthesia as indicated by a lack of animal movement or spontaneous respiratory efforts.

\section{Pure diaphragm separation}

All the animals were sacrificed using the $\mathrm{CO}_{2}$ asphyxia method. Diaphragm muscles were dissected, and blood, fat, and tendons were removed. The resultant pure diaphragm muscles were maintained in the F12 medium.

\section{Diaphragm muscle digestion}

The diaphragm was weighed and chopped into a fine slurry in $800 \mu \mathrm{L} \mathrm{TC}$ until it could pass through a 10$\mathrm{mL}$ pipette freely. The fine slurry was transferred into a $15-\mathrm{mL}$ Falcon tube and mixed with $9.2 \mathrm{~mL}$ TC. The mixture was incubated at $37^{\circ} \mathrm{C}$ for 35 min with gentle agitation. Subsequently, the Falcon tube was allowed to stand for $2 \mathrm{~min}$, and $9.5 \mathrm{~mL}$ supernatant was collected into a $50-\mathrm{mL}$ Falcon tube containing 8 $\mathrm{mL}$ FBS. The above-mentioned steps were repeated three times to completely digest the muscle. Finally, the digested muscle suspension was filtered through an 80 -micron nylon cloth and centrifuged at 1,800 rpm $(688 \mathrm{~g})$ for $10 \mathrm{~min}$ at $4^{\circ} \mathrm{C}$. The single cells were resuspended and harvested.

\section{MACS isolation}

The enzymolysis cell sample was resuspended in $80 \mu \mathrm{L}$ buffer per gram tissue, and labeled with the specific antibody in $20 \mu \mathrm{L} \mathrm{SC}$ isolation at $4{ }^{\circ} \mathrm{C}$ for $15 \mathrm{~min}$. MS column was placed on the magnetic rack, followed by pre-equilibration using PBS containing $1 \%$ FBS. The cell suspension was applied to the column, and the unlabeled cells were collected.

After centrifugation, the cell pellet was resuspended at a density of $10^{6}$ cells per $80 \mu \mathrm{L}$ buffer, and mixed with $20 \mu \mathrm{L}$ anti-integrin a7 microbeads, followed by incubation at $4^{\circ} \mathrm{C}$ for $15 \mathrm{~min}$. Another MS column was placed on the magnetic rack, followed by pre-equilibration. Labeled cells were loaded onto the 
column. The column was then removed from the magnetic field and washed by $1 \mathrm{~mL}$ PBS containing $1 \%$ FBS. The target cells (diaphragm satellite cells) were collected.

\section{Cell culture and view division}

The matrigel medium was prepared and kept at $4^{\circ} \mathrm{C}$. After the cell number was determined, the diaphragm satellite cells were seeded into 12 -well plates at a density of $1.5 \times 10^{4}$ per well with $400 \mu \mathrm{L}$ medium. The cells were cultured at $37^{\circ} \mathrm{C}$ for 4 days. Subsequently, the view field of the fluorescence microscope was divided into 8-10 parts to observe for accurate counting (Fig. 2).

\section{Immunofluorescence detection}

The cells were stained with $0.03 \mathrm{mg} / \mathrm{mL}$ BrdU for $24 \mathrm{~h}$, and sequentially incubated with acetone and 1.5 $\mathrm{M} \mathrm{HCl}$. Next, the cells were blocked with serum for $1 \mathrm{~h}$. Subsequently, the cells were subjected to incubation with the primary antibody $(1: 1,000)$ and secondary antibody $(1: 500)$. After fixed with 1:5,000 Hoechest and covered using coveslips, the cells were observed under Zeiss M2 fluorescence microscope. The proliferation characteristics of satellite cells were determined according to the intensity of blue color from BrdU immunofluorescence staining.

To determine the differentiation characteristics of satellite cells, cells were fixed with 4\% PFA and blocked in blocker buffer. Subsequently, the cells were labeled with primary antibody (MYH3, 1:25) and secondary antibody (F-488-IgG, 1:500). Next, cells were fixed with 1:5,000 Hoechest and covered using coverslips. The cells were observed under Zeiss M2 fluorescence microscope, and the differentiation characteristics of satellite cells were determined according to the intensity of blue color.

\section{Quantitative real-time PCR ( $q R T-P C R)$}

Total RNA was isolated from satellite cells using TRIzol regent (ThermoFisher, USA) and then reversely transcribed into cDNA. The expressions of MyoD and myogenin were assessed using qRT-PCR on a StepOne plus system (ABI Instrument, USA). HPRT1 was selected as the housekeeping gene. The primers were designed using Primer3.0, and the primer sequences were as follows: MyoD 5'-

AGAATGGCTACGACACCGCC-3', 5'-GCTGTCTGTGGAGATGCGCT-3'; myogenin 5'GAGGAGCGCGATCTCCGCTA-3'; 5'-GTCAGCCGCGAGCAAATGAT-3'; HPRT1 5'-

CATGCCATGGCATACAGTGAAAAGGTGATC-3'; 5'-TGACAAGCTTGTGTGCCGCCTGGGCACT-3'. Briefly, after an initial denaturation step at $94{ }^{\circ} \mathrm{C}$ for $10 \mathrm{~min}$, the amplifications were carried out with 40 cycles at a melting temperature of $94{ }^{\circ} \mathrm{C}$ for $30 \mathrm{~s}$, and an annealing temperature of $60^{\circ} \mathrm{C}$ for $1 \mathrm{~min}$. The relative expressions of target genes were calculated using the $2^{-\Delta \Delta C t}$ method.

\section{Image software and statistical analysis}


Green or blue cells were counted separately, and the ratio was determined. The positive area was calculated with Image software.

All data were expressed as mean $\pm S D$, and an independent sample t-test was selected to analyze the variables. $\mathrm{P} \otimes 0.05$ was considered statistically significant.

\section{Results}

\section{Optimized isolation for diaphragm satellite cells}

Generally speaking, the muscle weight of the diaphragm from C57 mouse was approximately $160 \mathrm{mg}$, and $1.5 \times 10^{5}$ single diaphragm satellite cells could be harvested from a single diaphragm through MACS using the optimized parameters. These findings laid a preliminary foundation to further investigate the biological characteristics of diaphragm satellite cells and their related mechanisms.

\section{$2 \mathrm{MV}$ reduces the proliferation of satellite cells}

We found that the cell morphology of satellite cells in the control group was normal, showing obvious proliferation. However, the proliferation of satellite cells in the MV group was significantly reduced, exhibiting apparent disintegration (Figure 3A and 3B).

All the satellite cells from the control or MV group were stained with BrdU after 4 days of incubation. We found that the cell number of the control group was greater compared with the MV group (Figure $3 \mathrm{C}$ and $3 D$ ), suggesting that the cell proliferation ability in the control group was greater compared with the MV group. However, such finding should be validated using other methods.

\section{$3 \mathrm{MV}$ changes the cell morphology of diaphragm satellite cells}

All the satellite cells were labeled with specific differentiation antibody after 4 days of incubation. We found that the diaphragm satellite cells in the control group exhibited normal cell morphology, and the nucleus was distributed orderly in fiber bundles. However, the satellite cells of the MV group showed irregular cell morphology, and the nucleus was also irregular and scattered, indicating that the cells of the MV group tended to differentiate (Figure 4C and 4D).

\section{$4 \mathrm{MV}$ affects proliferation/differentiation of diaphragm satellite cells}


The cell number was counted from randomly selected areas (Fig. 5A, B, C, D). We found that the proliferation ratio of diaphragm satellite cells was decreased by $\mathrm{MV}$ from $88.74 \%$ to $81.92 \%$, while the differentiation ratio was increased from $17.94 \%$ to $27.58 \%$ (Fig. 5E).

\section{The expressions of MyoD and myogenin are up-regulated upon MV}

MyoD and myogenin are promising impact factors on the diaphragm in terms of proliferation or differentiation [Yablonka-Reuveni Z, Anderson JE, 2006]. Fig. 6 shows that the expressions of both abovementioned genes were significantly up-regulated upon MV for $6 \mathrm{~h}$ compared with the control group, supporting the differentiation results of diaphragm satellite cells.

\section{Discussion}

Currently, no reliable approach is available to obtain diaphragm satellite cells, which has greatly restricted further research on relevant mechanisms. In the present study, we aimed to solve this problem with MACS. It is known that MACS can positively select target cells using magnetic beads coated with specific high-affinity monoclonal antibodies [19]. Previous studies have shown that MACS can isolate healthy hematopoietic stem/progenitor cells (HSPCs), astrocytes, and iNKT cells [20-22]. Moreover, target cell isolation through MACS is 4-6 times more efficient than FACS [23]. Through a series of MACS parameter optimization, we successfully established a stable method to obtain single diaphragm satellite cells. The muscle weight of a single diaphragm from C57 mouse was about $150 \mathrm{mg}$, and $1.5 \times 10^{5}$ single satellite cells could be harvested from it. These findings laid a preliminary foundation to further investigate the biological characteristics of diaphragm satellite cells and their related mechanisms.

MV is a life-saving supportive therapy for patients with acute respiratory failure, while it is often referred to as a two-edged sword for patients in cardiogenic shock [24]. MV has been associated with some major complications, such as infection, barotrauma, tracheal injury, and ventilator-induced lung injury [25], especially the ventilator-induced difficulty in weaning [26]. MV can shorten the diaphragm, and induce VIDD, such as damage, disuse, or even weaning failure [27, 28]. A previous study has indicated that diaphragmatic strength and endurance play critical roles in successfully weaning patients from MV [29]. More precisely, MV can cause a sudden interruption of diaphragmatic contractile activity, in which the energetic requirements of the muscle are abruptly reduced [30]. The decreased compound muscle action potential after MV suggests that impaired muscle fiber membrane excitability and/or excitationcontraction coupling participate in such process, leading to disuse atrophy [31, 32]. The relationship between diaphragm muscle strength and ventilation time is descending logarithmically [33]. Taken together, the mechanisms underlying the MV-induced diaphragm damage potentially involve a multistep process, including muscle atrophy, oxidative loads, structural damage, and muscle fiber remodeling. However, such mechanisms have not been well defined. 
In the present study, we speculated that the proliferation and differentiation characteristics of diaphragm satellite cells played a critical role in weaning difficulties from MV. It is known that in adult muscle, satellite cells are the myogenic progenitors[13]. In the dystrophic ( $\mathrm{mdx}$ ) mouse model of human Duchenne muscular dystrophy, satellite cells participate in myofiber regeneration []. It has been also reported that the atrophy of the diaphragm is faster compared with other skeletal muscles under adverse stimulation [34]. Myofibers isolated from dystrophic muscles show a more rapid differentiation, although there is no statistical significance. Furthermore, myofibers purified from mdx mice exhibit an earlier differentiation compared with the control group (C57 mice). More interestingly, myogenic cells from the dystrophic (mdx) mouse display an accelerated differentiation [13]. In our present study, we also found that diaphragm satellite cells tended to differentiate after $6 \mathrm{~h}$ of MV. This result was consistent with the reduced diaphragmatic flexibility, disuse atrophy, and dysfunction after MV.

The interplay between proliferation and differentiation is tightly regulated by the helix-loop-helix family of muscle-specific transcription factors. There are four members in this family, including Myf5, MyoD, myogenin, and MRF4, which are often regarded as myogenic regulatory factors (MRFs) [13]. The latest research has shown that MLL1 can facilitate the proliferation of myoblasts and Pax7-positive satellite cells by epigenetically regulating Myf5 [35]. The myogenic factor MyoD can regulate skeletal muscle differentiation by interacting with a variety of chromatin-modifying complexes [36]. However, bexarotene enhances the differentiation and fusion of myoblasts through a direct regulation of MyoD expression, coupled with an augmentation of myogenin protein [37 ]. PARP1 depletion can boost the expressions of MyoD targets, such as p57, myogenin, Mef2C, and p21136区. In summary, Myf5, MyoD, myogenin, and MRF4 play a crucial role in directing satellite cell function to regenerate skeletal muscle, linking the genetic control of developmental and regenerative myogenesis [38]. In the present study, we partly confirmed that the expressions of MyoD and myogenin in diaphragm satellite cells were significantly increased after $6 \mathrm{~h}$ of MV. These findings might help explain the stem cell differentiation tendency and diaphragm dysfunction after MV.

\section{Conclusions}

We developed a feasible and efficient approach to isolate diaphragm stem cells through optimized MACS, which solved the bottleneck in this research field. Meanwhile, it was clarified that diaphragm stem cells tended to differentiate after MV, and the expressions of MyoD and myogenin were significantly increased. Taken together, our findings provided valuable insights into deeper mechanisms of VIDD.

\section{Abbreviations}




\begin{tabular}{|c|c|}
\hline MV & Mechanical ventilation \\
\hline BrdU & Synonyms: 5-Bromo-2'-deoxyuridine \\
\hline MACS & Magnetic-activated cell sorting \\
\hline MYH3 & Myosin heavy chain 3 \\
\hline MyoD & Myogenic Differentiation Antigen \\
\hline qPCR & Quantitative Real-time Polymerase Chain Reaction \\
\hline VT & Volume of Tidal \\
\hline VIDD & Ventilator-induced Diaphragmatic Dysfunction \\
\hline Pax7 & Paired box protein 7 \\
\hline CXCL12 & Chemokine (C-X-C motif) ligand 12 \\
\hline MuSCs & Muscle satellite cells \\
\hline HO-1 & Heme Oxygenase-1 \\
\hline IACUC & Institutional Animal Care and Use Committee \\
\hline SPF & Specific Pathogen Free \\
\hline RR & Respiratory Rate \\
\hline PEEP & Positive End Expiratory Pressure \\
\hline TC & solution( $50 \mathrm{ml} \mathrm{TC}=42 \mathrm{ml} \mathrm{F12+4ml} \mathrm{1 \% Trypsin+4ml} \mathrm{1 \% Collagenase} \mathrm{D)}$ \\
\hline PBS & Phosphate Buffer Saline \\
\hline FBS & Fetal Bovine Serum \\
\hline PFA & Paraformaldehyde \\
\hline MS & Magnetic Separation \\
\hline SD & Standard Deviation \\
\hline CDK & Cyclin-dependent kinases \\
\hline HSPCs & Haematopoietic Stem/Progenitor Cells \\
\hline iNKT & Invariant Natural Killer T \\
\hline Myf5 & Myogenic factor 5 \\
\hline MRF4 & Myogenic regulatory factor 4 \\
\hline MRFs & Myogenic regulatory factors \\
\hline
\end{tabular}




\section{Declarations}

\section{Ethics approval and consent to participate}

Not applicable

\section{Consent for publication}

Not applicable

\section{Availability of data and material}

All data generated or analysed during this study are included in this published article.

\section{Competing interests}

All authors declared no potential conflicts.

\section{Funding}

This work was supported by the Beijing Natural Science Foundation [No. 7182071] and National Natural Science Foundation of China [No. 81503399].

\section{Authors' contributions}

Junying Ding performed experiments, conducted data analysis, and drew the manuscript. Qian Li, Feng Liang, and Salyan Bhattarai contributed to the tests. Qingquan Liu provided related financial support.

\section{Acknowledgments}

This work was performed at Mcgill University Health Centre. The authors are grateful to Dr. Basil Petrof for scientific advice.

\section{References}

1. Major VJ, Chiew YS, Shaw GM, et al. Biomedical engineer's guide to the clinical aspects of intensive care mechanical ventilation. Biomed Eng Online. 2018;17:169.

2. Heder de Vries A, Jonkman Z-H, Shi, et al. Assessing breathing effort in mechanical ventilation: physiology and clinical implications. Ann Transl Med. 2018;6:387. 
3. Sanfilippo F, Di Falco D, Noto A, et al. Association of weaning failure from mechanical ventilation with transthoracic echocardiography parameters: a systematic review and meta-analysis. $\mathrm{Br} \mathrm{J}$ Anaesth. 2020;7:059.

4. Formenti P, Umbrello $M$, Dres $M$, et al. Ultrasonographic assessment of parasternal intercostal muscles during mechanical ventilation. Ann Intensive Care. 2020;10:120.

5. Dres M. Alexandre Demoule. Diaphragm dysfunction during weaning from mechanical ventilation: an underestimated phenomenon with clinical implications. Crit Care. 2018;22:73.

6. Liang F, Emeriaud G, Rassier DE, et al. Mechanical ventilation causes diaphragm dysfunction in newborn lambs. Crit Care. 2019;23:123.

7. Larsson L, Friedrich O. Critical Illness Myopathy (CIM) and Ventilator-Induced Diaphragm Muscle Dysfunction (VIDD): Acquired Myopathies Affecting Contractile Proteins. Compr Physiol. 2016;7:105-12.

8. Evans D, Shure D, Clark L, et al. Temporary transvenous diaphragm pacing vs. standard of care for weaning from mechanical ventilation: study protocol for a randomized trial. Trials. 2019;20:60.

9. Petrof BJ, Jaber S, Matecki S. Ventilator-induced Diaphragmatic Dysfunction. Curr Opin Crit Care. 2010;16:19-25.

10. Verma M, Asakura A. Efficient Single Muscle Fiber Isolation from Alcohol-Fixed Adult Muscle following $\beta$-Galactosidase Staining for Satellite Cell Detection. J Histochem Cytochem. 2011;1:60-7.

11. Randolph ME, Pavlath GK. A muscle stem cell for every muscle: variability of satellite cell biology among different muscle groups. Front Aging Neurosci. 2015;7:190.

12. Maeda Y, Yonemochi Y, Nakajyo Y, et al. CXCL12 and osteopontin from bone marrow-derived mesenchymal stromal cells improve muscle regeneration. Sci Rep. 2017;7:3305.

13. Yablonka-Reuveni Z, Anderson JE. Satellite cells from dystrophic ( $\mathrm{mdx}$ ) mice display accelerated differentiation in primary cultures and in isolated myofibers. Dev Dyn. 2006;235:203-12.

14. Han WM, Mohiuddin M, Anderson SE, et al. Co-delivery of Wnt7a and muscle stem cells using synthetic bioadhesive hydrogel enhances murine muscle regeneration and cell migration during engraftment. Acta Biomater. 2019;94:243-52.

15. Wada E, Tanihata J, Iwamura A, et al. Treatment with the anti-IL-6 receptor antibody attenuates muscular dystrophy via promoting skeletal muscle regeneration in dystrophin-/utrophin-deficient mice. Skelet Muscle. 2017;7:23.

16. Pietraszek-Gremplewicz K, Kozakowska M, Bronisz-Budzynska I, et al. Heme Oxygenase-1 Influences Satellite Cells and Progression of Duchenne Muscular Dystrophy in Mice. Antioxid Redox Signal. 2018;2:7435.

17. Worraphan S, Thammata A, Chittawatanarat K, et al. Effects of Inspiratory Muscle Training and Early Mobilization on Weaning of Mechanical Ventilation: A Systematic Review and Network Metaanalysis. Arch Phys Med Rehabil. 2020;07:004. 
18. Pascal Stuelsatz1, Paul Keire1. Almuly R, et al. A Contemporary Atlas of the Mouse Diaphragm: Myogenicity, Vascularity, and the Pax3 Connection. J Histochem Cytochem.2012; 60: 638-57.

19. Weiss R, Gerdes W, Leonhardt F, et al. A comparative study of two separation methods to isolate monocytes. Cytometry Part A the Journal of the International Society for Analytical Cytology. 2018;2:1-8.

20. Razmkhah F, Ghasemi S, Soleimani M, et al. LY86, LRG1 and PDE9A genes overexpression in umbilical cord blood hematopoietic stem progenitor cells by acute myeloid leukemia (M3) microvesicles. Exp Hematol Oncol. 2019;8:23.

21. Scheuer T, Klein LS, Bührer C, et al. Transient Improvement of Cerebellar Oligodendroglial Development in a Neonatal Hyperoxia Model by PDGFA Treatment. Dev Neurobiol. 2019; 22667.

22. Park JY, Kwon J, Kim EY, et al. iCD24 Cell Depletion Permits Effective Enrichment of Thymic NKT Cells While Preserving Their Subset Composition. Immune Netw. 2019;19:e14.

23. Sutermaster BA, Darling EM. Considerations for high-yield, high-throughput cell enrichment: fluorescence versus magnetic sorting. Sci Rep. 2019;9:227.

24. Smith BK, Falk DJ. Mechanical Ventilation for Duchenne Muscular Dystrophy: Sinner or Saint? Muscle Nerve. 2018;57:353-5.

25. Blough JT, Purnell CA, Chow I, et al. Wound Complications, Additional Ventilation Requirement, Prolonged Stay, and Readmission in Primary Palatoplasty: A Risk Factor Analysis of 3616 Patients. Plast Reconstr Surg. 2019;144:1150-7.

26. Windisch W, Dellweg D, Geiseler J, et al. Prolonged Weaning from Mechanical Ventilation. Dtsch Arztebl Int. 2020;117:197-204.

27. Dres M, Demoule A. Beyond Ventilator-induced Diaphragm Dysfunction New Evidence for Critical Illness-associated Diaphragm Weakness. Anesthesiology. 2019;131:462-3.

28. Berger D, Bloechlinger $S$, von Haehling $S$, et al. Dysfunction of respiratory muscles in critically ill patients on the intensive care unit. Journal of Cachexia Sarcopenia Muscle. 2016;7:403-12.

29. Liu YY, Li LF. Ventilator-induced diaphragm dysfunction in critical illness. Exp Biol Med (Maywood). 2018;243:1-9.

30. Marini JJ, Rocco PRM, Gattinoni L. Static and Dynamic Contributors to Ventilator-induced Lung Injury in Clinical Practice. Pressure, Energy, and Power. Am J Respir Crit Care Med. 2020;201:767-74.

31. Lawler JM, Hu Z, Barnes WS. Effect of reactive oxygen species on $\mathrm{K}+$ contractures in the rat diaphragm. J Appl Physiol. 1998;84:948-53.

32. O'Leary AJ, Drummond SE, Edge D, et al. Diaphragm Muscle Weakness Following Acute Sustained Hypoxic Stress in the Mouse Is Prevented by Pretreatment with N-Acetyl Cysteine. Oxid Med Cell Longev. 2018; 2018: 4805493.

33. Di Mussi R, Spadaro S, Mirabella L, et al. Impact of prolonged assisted ventilation on diaphragmatic efficiency: NAVA versus PSV. Crit Care. 2016;20:1. 
34. Mrozek S, Jung B, Petrof BJ, et al. Rapid onset of specific diaphragm weakness in a healthy murine model of ventilator-induced diaphragmatic dysfunction. Anesthesiology. 2012;117:560-7.

35. Cai S, Zhu Q, Guo C, et al. MLL1 promotes myogenesis by epigenetically regulating Myf5. Cell Prolif. 2020;2:e12744.

36. Matteini F, Andresini O, Petrai S, et al. Poly(ADP-ribose) Polymerase 1 (PARP1) restrains MyoDdependent gene expression during muscle differentiation. Sci Rep. 2020;10:15086.

37. Hamed M, Khilji S, Dixon K, et al. Insights into interplay between rexinoid signaling and myogenic regulatory factor-associated chromatin state in myogenic differentiation. Nucleic Acids Res. 2017;19:11236-48.

38. Zammit PS. Function of the myogenic regulatory factors Myf5, MyoD, Myogenin and MRF4 in skeletal muscle, satellite cells and regenerative myogenesis. Semin Cell Dev Biol. 2017;72:19-32.

\section{Figures}




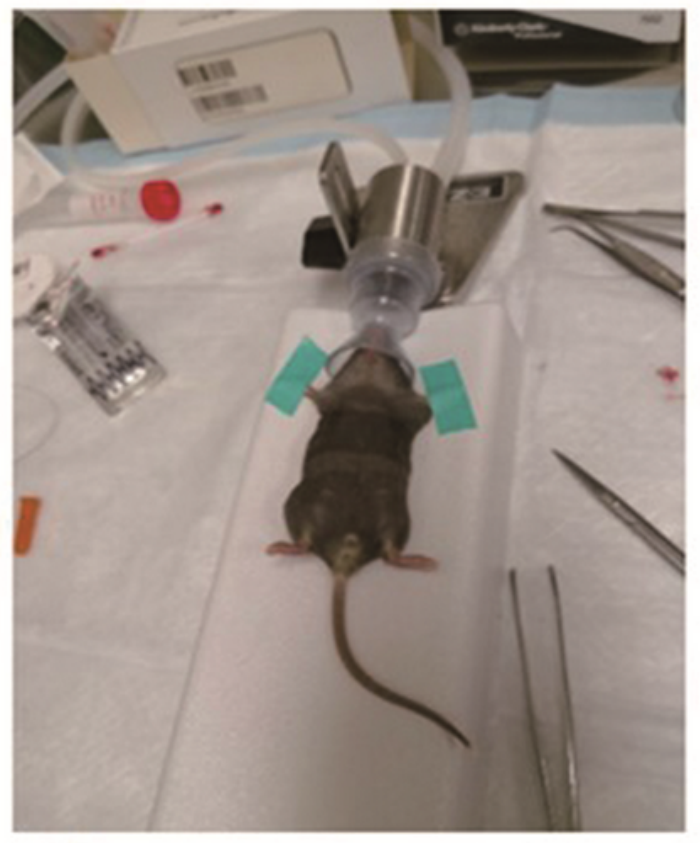

A

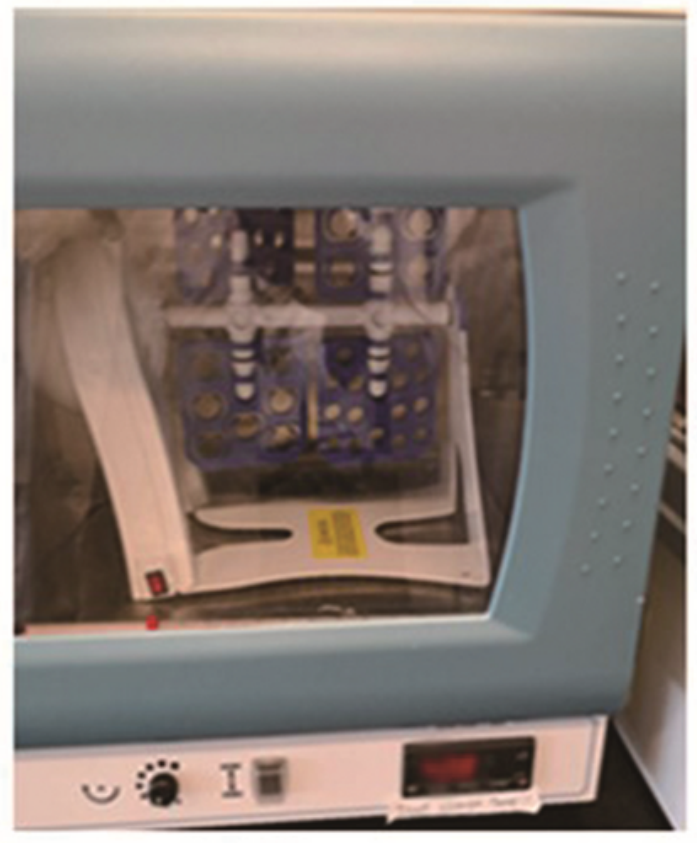

C

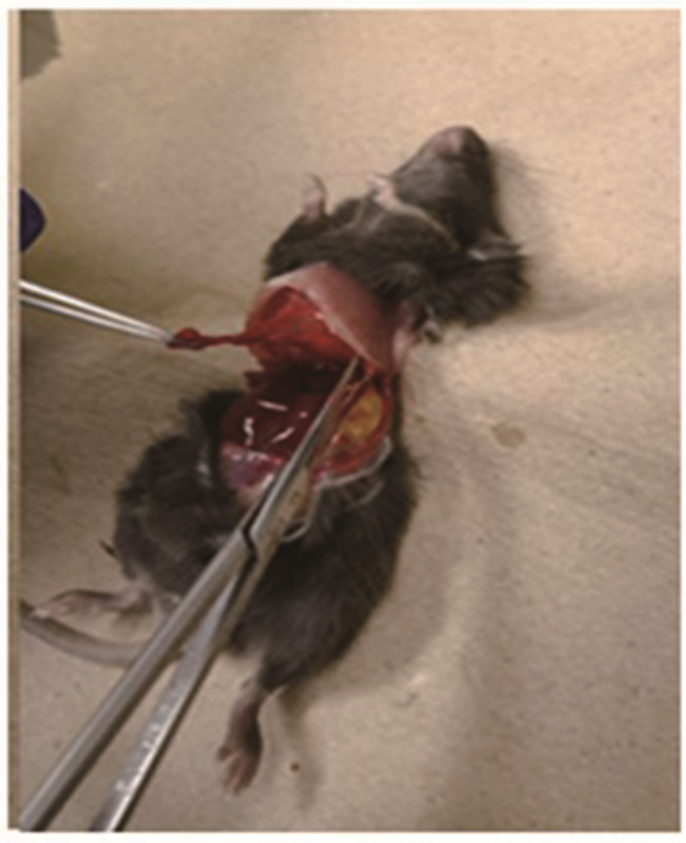

B

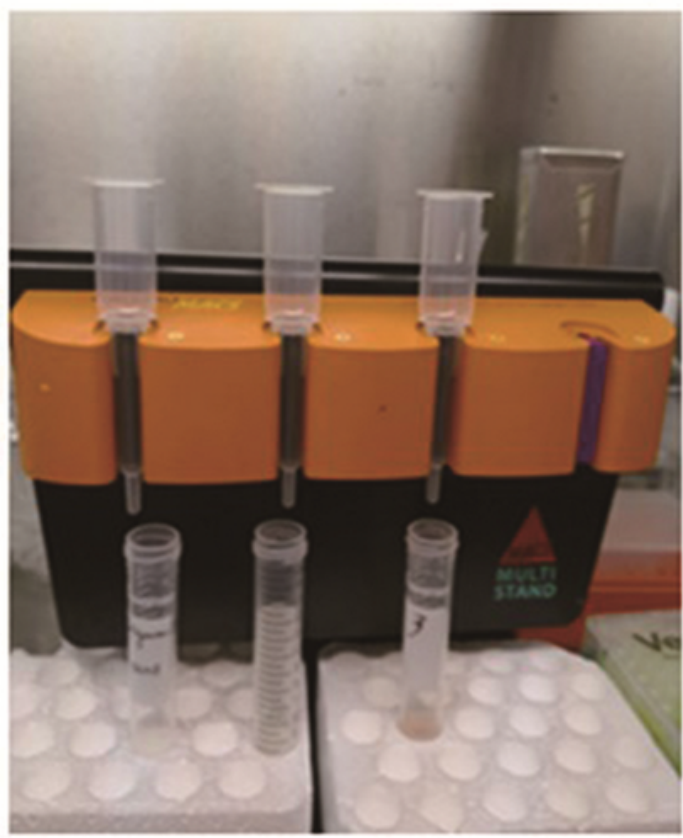

D

\section{Figure 1}

Collection of diaphragm and satellite cells A MV: Inhalation oxygen partial pressure (0.21), VT $10 \mu \mathrm{L} \cdot \mathrm{k} \otimes 1$, RR 150-170/min, PEEP 3-4 cm H2O; B Dissection of diaphragm muscle: 150 $\pm 30 \mathrm{~g} /$ diaphragm muscle; C Diaphragm enzymolysis: $37^{\circ} \mathrm{C}, 30 \mathrm{~min}$, three times; D Isolation of satellite cells through MACS: about $1.5 \times 105$ cells/diaphragm; 


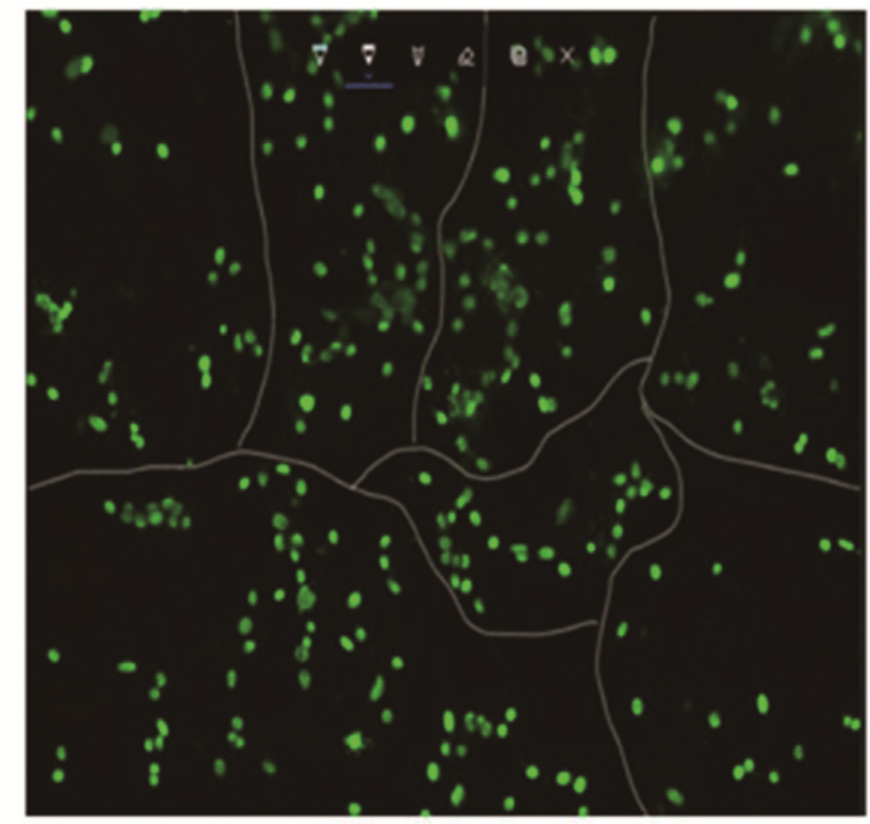

A

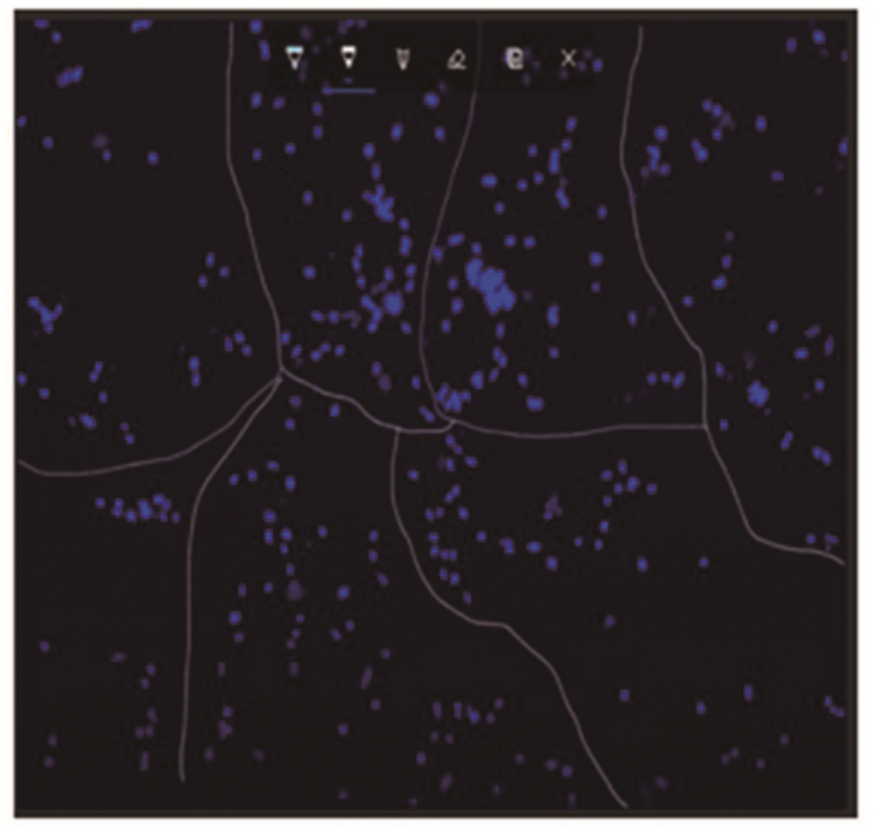

B

Figure 2

View division of fluorescence microscope Green fluorescence stands for cell proliferation (Fig. 2A), and blue fluorescence indicates cell differentiation (Fig. 2B). Slides were observed using fluorescence microscopy. Each selected view was divided into 8-10 parts. To ensure accuracy, the experiment was repeated four times by two researchers. 


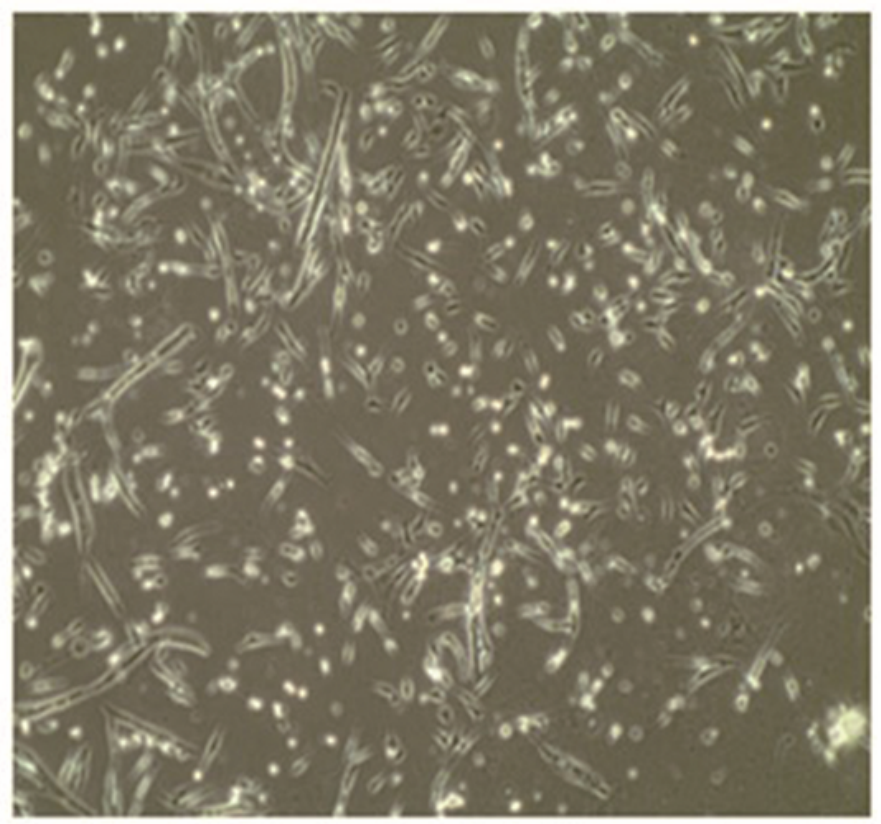

A

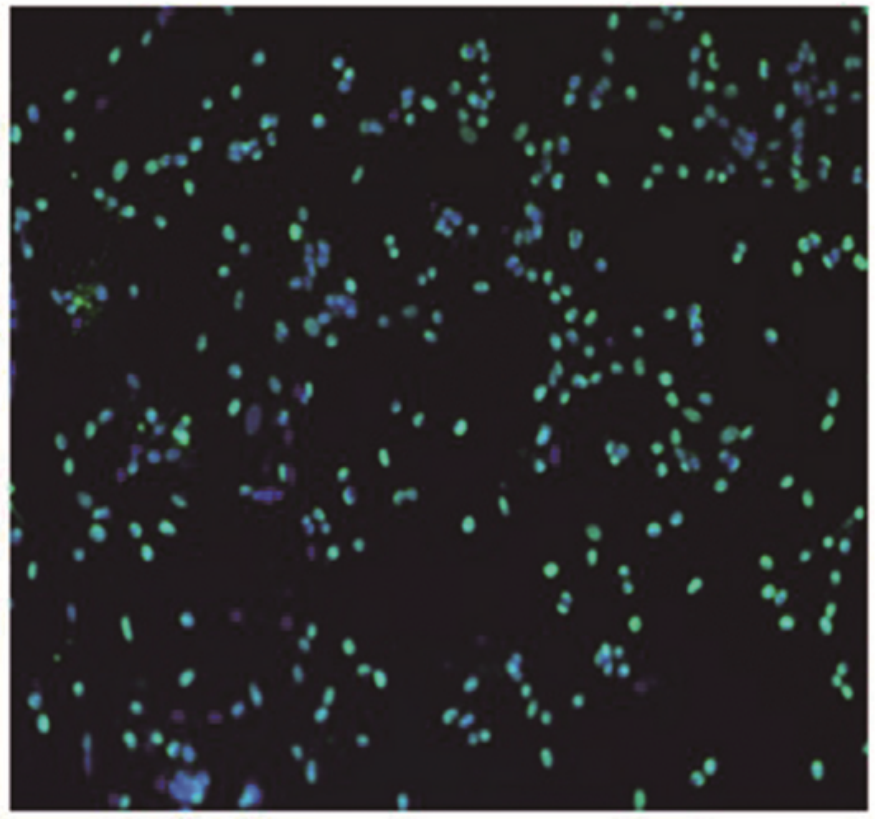

C

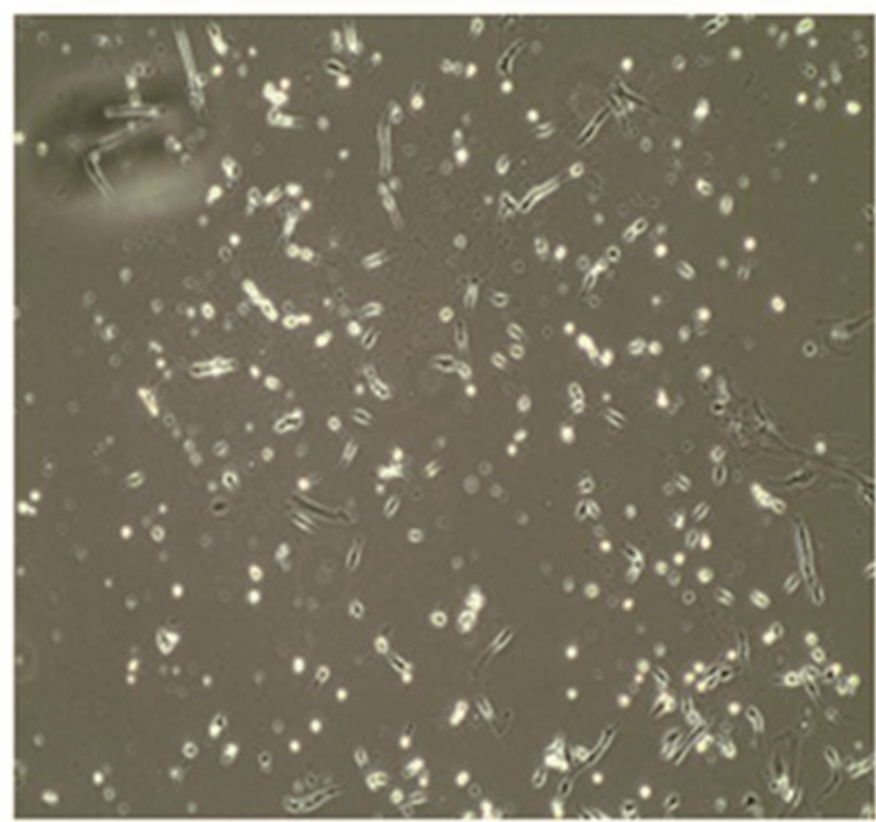

B

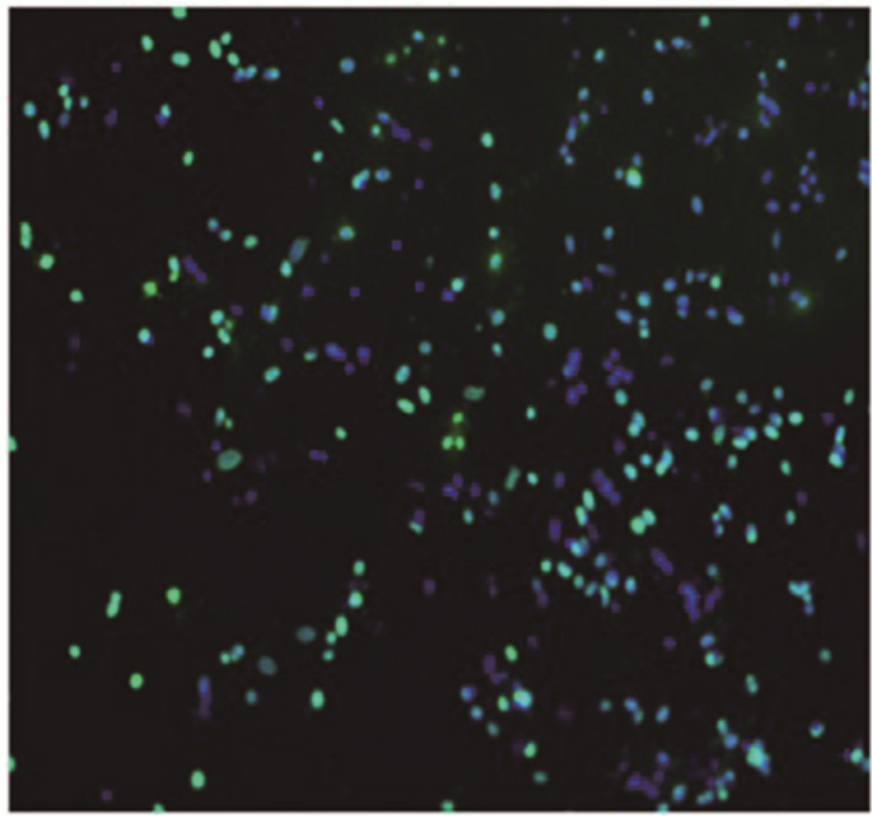

D

\section{Figure 3}

Proliferation assay of diaphragm satellite cells Satellite cells were isolated from the diaphragm muscle of C57 mice with or without $6 \mathrm{~h}$ of MV, followed by in vitro cultivation for 4 days (Fig. 3B and A) and 5 days (Fig. 3D and C). Cells were maintained in the culture medium supplemented with $0.03 \mathrm{mg} / \mathrm{mL} \mathrm{BrdU}$ and allowed to undergo spontaneous proliferation. Cells were immunostained for proliferation assay and counterstained with DAPI to show the nucleus. Initially, the cells showed equivalent density in the control 
or experimental group. At the end of the experiment, the cell number was counted in both groups, and the proliferation characteristics of satellite cells were determined. Blue fluorescence represents proliferating cells. Magnification $40 \times 10$. A Diaphragm satellite cells in the control group on day 4; B Diaphragm satellite cells in the MV group on day 4; C Diaphragm satellite cells in the control group stained by BrdU after 5 days; D Diaphragm satellite cells in the MV group stained by BrdU after 5 days;

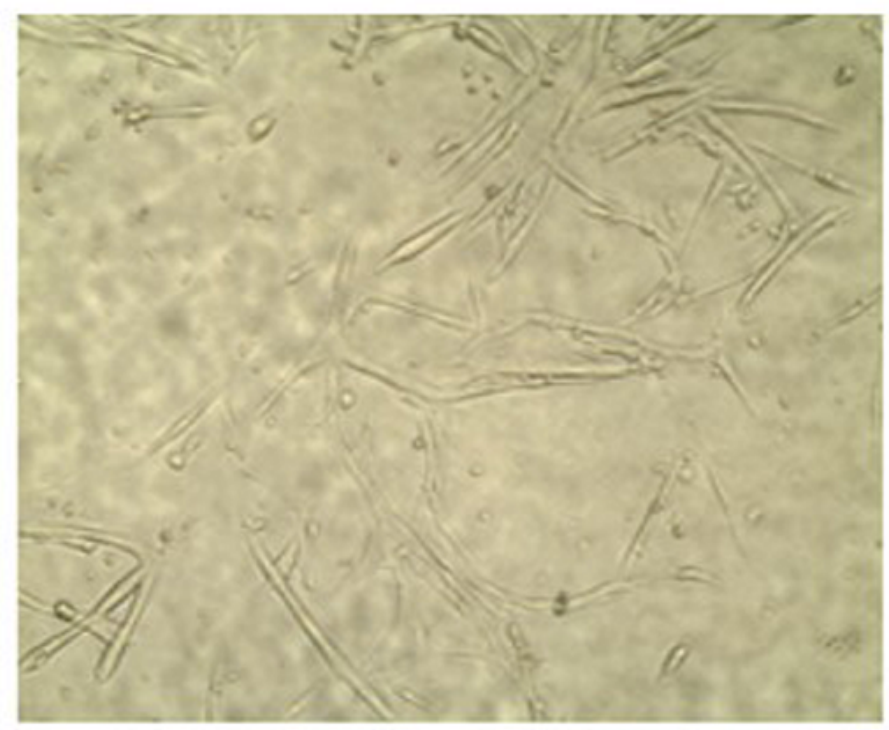

A

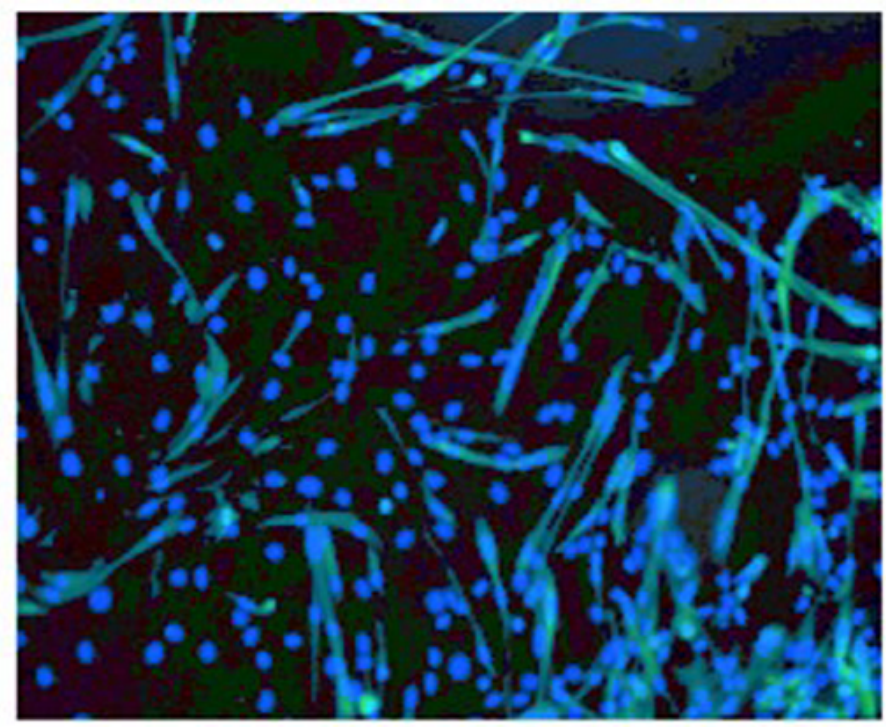

C
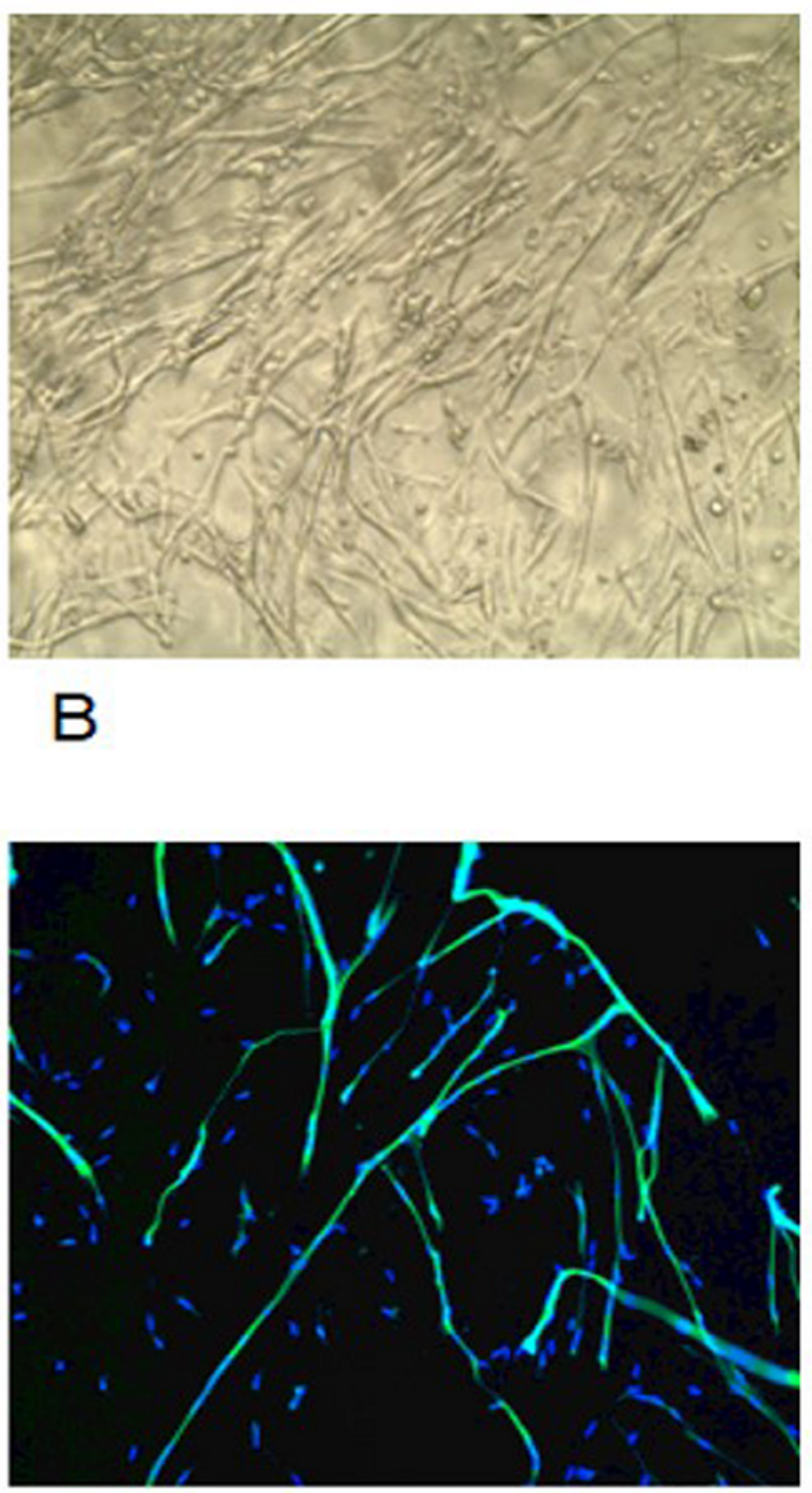

$\mathrm{D}$

Figure 4

Differentiation assay of diaphragm satellite cells Satellite cells were isolated from the diaphragm muscle of C57 mice with or without $6 \mathrm{~h}$ of MV, followed by in vitro cultivation for 4 days (Fig. 4B and A). Cells were fixed with $4 \%$ PFA and immunostained for differentiation assay. Initially, the cells showed equivalent 
density in the control or experimental group. At the end of the experiment, the differentiation of cells was observed under a fluorescence microscope, and the differentiation characteristics of satellite cells were determined. Green fluorescence represents differentiating cells. Magnification 40×10. A Diaphragm satellite cells in the control group; B Diaphragm satellite cells in the MV group; C Diaphragm satellite cells stained by differentiation maker in the control group; D Diaphragm satellite cells stained by differentiation maker in the MV group;
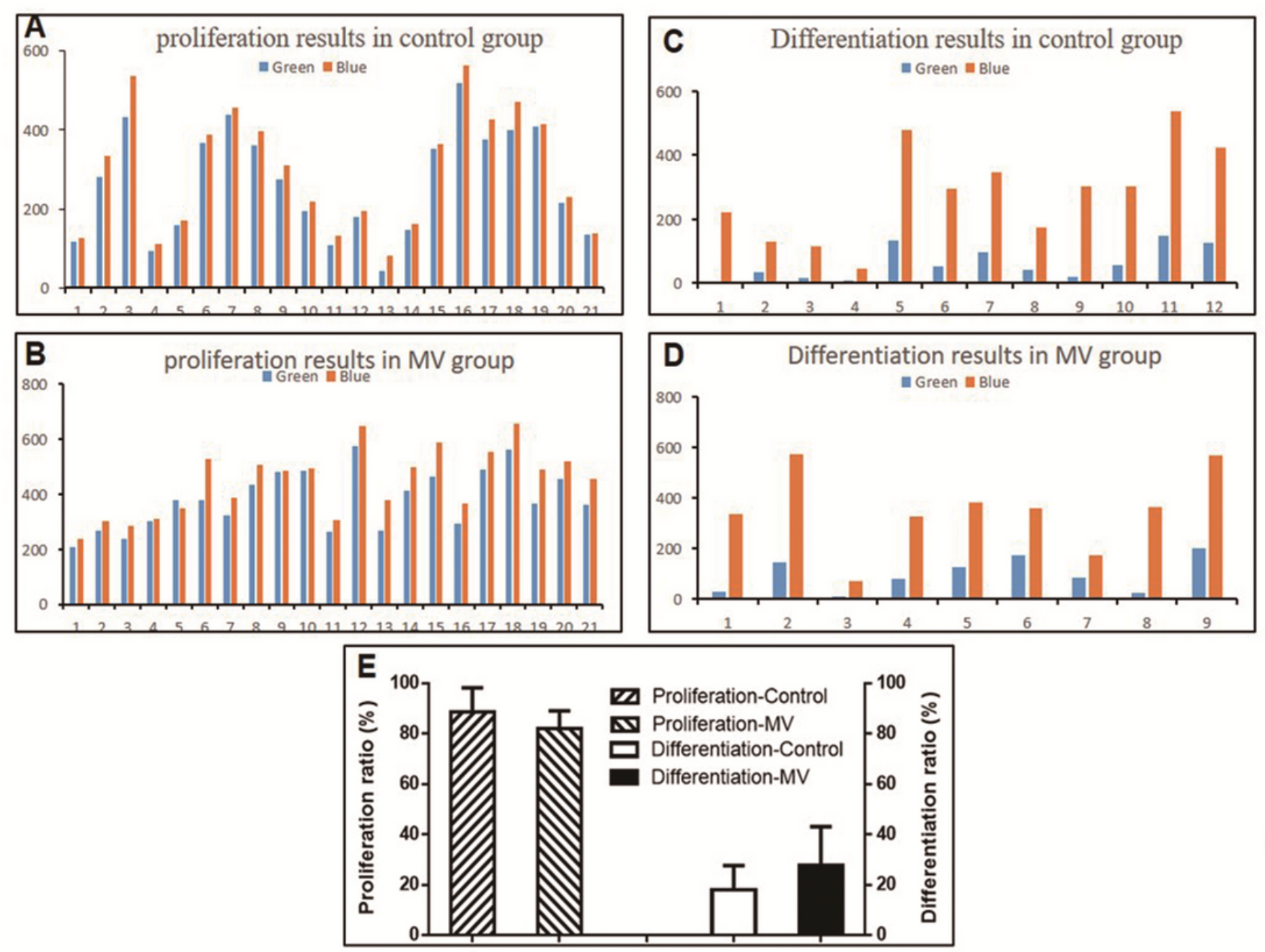

\section{Figure 5}

The distributions of proliferating satellite cells or differentiating satellite cells A Proliferation results in the control group; B Proliferation results in the MV group; C Differentiation results in the control group; D Differentiation results in the MV group; E Proliferation and differentiation ratio; The distributions of proliferating satellite cells (Fig. 5A, B) or differentiating satellite cells (Fig. 5C, D) after MV or not in stem cells isolated from the diaphragm. Cells were maintained in the culture medium for 4 days before specific staining. With image software, the proliferation and differentiation ratio was calculated, as shown in Fig. $5 \mathrm{E}$. 


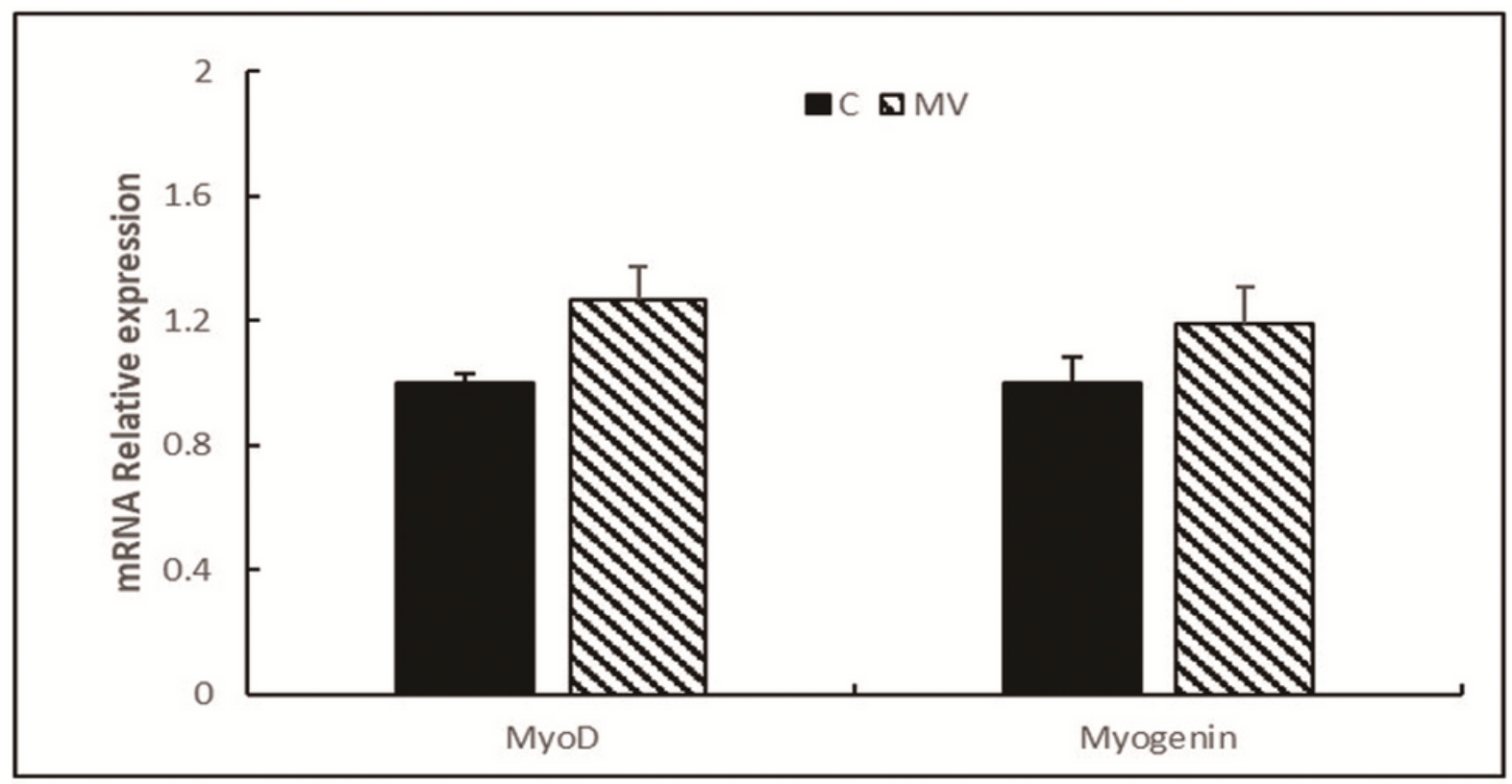

Figure 6

The relative expression levels of MyoD and myogenin in different groups. Data are presented as mean \pm $\operatorname{SD}(n=3)$. 